\title{
Prevalence and associated factors of active trachoma among 1-9 years old children in Deguatemben, Tigray, Ethiopia, 2018: community cross-sectional study
}

Gebremeskel Reda ${ }^{1 \dagger}$, Dejen Yemane ${ }^{2 \dagger}$ and Aregawi Gebreyesus ${ }^{2 *+}$

\begin{abstract}
Background: Trachoma is a contagious infection of the eye. World Health Organization recommended three rounds of mass drug administration in districts where the prevalence of trachomatous follicular (TF) is $\geq 10 \%$ in children aged 1-9years. Mass drug distribution was given to residents for three consecutive years with more than $90 \%$ coverage. However, the prevalence and associated factors of active trachoma in the study community after the intervention was not yet determined. Thus, this deals with the prevalence and associated factors of active trachoma among children aged 1-9 years.

Methods: We conducted a Community based cross-sectional study among 502 children aged 1-9 in March 2018 in Deguatemben. A multi-stage sampling technique was applied. Selected children were examined for trachoma using $2.5 \mathrm{x}$ binocular loupe and graded based on the WHO simplified grading system. Mothers were interviewed for factors associated with trachoma using a structured questionnaire. Data was entered on Epi-Info and exported to SPSS for analysis. Both descriptive and inferential analyses were done with $95 \%$ confidence intervals (Cls) at a $p$ value $<0.05$ for the final model.

Results: The prevalence of active trachoma was found 21.5\% (95\% Cl: 17.8-25.1\%). Being 1 to 4 years old [AOR $(95 \% \mathrm{Cl})=6.81(2.00-23.11)]$, not washing face $[\mathrm{AOR}(95 \% \mathrm{Cl})=9.31(1.13-77.66)]$, not using soap $[\mathrm{AOR}(95 \% \mathrm{Cl})=$ 5.84(1.87-18.21)], unclean face $[\mathrm{AOR}(95 \% \mathrm{Cl})=18.22(4.93-69.32)]$ and mother's knowledge $[\mathrm{AOR}(95 \% \mathrm{Cl})=$ $0.06(0.02-0.19)]$ were found as independent predictors.

Conclusion: The prevalence declined from the baseline, but it is still a public health problem in the district. Personal-related factors were found to be associated with the disease. Health education of "Facial cleanness" and related factors is recommended to increase knowledge of the mothers on their children's care in addition to the provision of antibiotics.
\end{abstract}

Keywords: Prevalence and associated factors, Active trachoma, Tigray, Ethiopia

\footnotetext{
* Correspondence: dc.aregawi@gmail.com

${ }^{\dagger}$ Gebremeskel Reda, Dejen Yemane and Aregawi Gebreyesus contributed equally to this work.

${ }^{2}$ College of Health Sciences, Mekelle University, P.O.BOX:1871 Mekelle, Tigray, Ethiopia

Full list of author information is available at the end of the article
}

C C The Author(s). 2020 Open Access This article is licensed under a Creative Commons Attribution 4.0 International License, which permits use, sharing, adaptation, distribution and reproduction in any medium or format, as long as you give appropriate credit to the original author(s) and the source, provide a link to the Creative Commons licence, and indicate if changes were made. The images or other third party material in this article are included in the article's Creative Commons licence, unless indicated otherwise in a credit line to the material. If material is not included in the article's Creative Commons licence and your intended use is not permitted by statutory regulation or exceeds the permitted use, you will need to obtain permission directly from the copyright holder. To view a copy of this licence, visit http://creativecommons.org/licenses/by/4.0/. The Creative Commons Public Domain Dedication waiver (http://creativecommons.org/publicdomain/zero/1.0/) applies to the data made available in this article, unless otherwise stated in a credit line to the data. 


\section{Background}

Trachoma is the leading cause of blindness resulted from repeated trachoma infection [1]. Infected eye secretions with an active infective stage of trachoma are the main source of trachoma infection and mode of transmission includes; direct eye to eye spread, contaminated fingers, indirect spread through sharing towels, pillows, and eye seeking flies [2].

According to World Health Organization (WHO) trachoma grading scheme trachoma is classified as Trachomatous inflammation follicular (TF), Trachomatous inflammation intense (TI), Trachomatous scarring (TS), Trachomatous trichiasis (TT) and Corneal opacity (CO) $[3,4]$. Active trachoma includes WHO grades of TF and/ or TI. Endemicity of trachoma is classified based on TF prevalence as non-endemic $(<5 \%)$, hypoendemic ( $\geq 5$ and $<10 \%)$, mesoendemic ( $\geq 10$ and $<30 \%)$ and hyper-endemic ( $\geq 30 \%)$ [5].

WHO Global Elimination of Trachoma (GET2020) Alliance recommends the implementation of the surgery, antibiotics, facial cleanness and environmental improvements (SAFE) strategy which tackles the disease through surgery to correct trichiasis, antibiotics to treat chlamydial infection and facial cleanliness and environmental improvements to suppress transmission of infection to eliminate the disease by 2020 [3].

Globally, about 150 million people suffer from active trachoma and 6 million people are blind due to its devastating complications and it is endemic in 42 countries: in Africa, in the Middle East, Central and South America, Asia and Australia with 200 million populations at risk living in these endemic countries [6-8].

Ninety-three percent (170 million) of the worlds' population at risk of trachoma live in Africa and Africa carries $72 \%$ of the global burden of trichiasis [9]. In Ethiopia 2.8 million people have low vision, 1.2 million lost their vision, 9 million children 1-9 years old have active trachoma and the prevalence of active trachoma is $40.1 \%$ [10].

All 34 rural woredas of Tigray had been mapped and revealed that 1.7 million (about 40\%) people live in hyper-endemic districts of the region and active trachoma prevalence among 1-9 years old children is $26.1 \%$. Deguatemben woreda is one of the 12 woredas with the prevalence of active trachoma among children $1-9$ years old $\geq 30 \%$ [11].

Different risk factors have been identified for trachoma from different settings which include; poor personal hygiene, lack of sanitary facilities and lack of accessible water for washing [12-16].

The WHO recommends annual mass treatment (MDA) of entire communities with oral azithromycin for at least 3 years if the prevalence of TF in 1-9-year-olds within a district or community exceeds $10 \%$ and with coverage of at least $80 \%$ of the population [17]. After the completion of the global trachoma mapping project (GTMP) in Tigray, Light for the World (the NGO that works to eliminate trachoma in Ethiopia) began supporting the regional trachoma elimination program in 2014 using the SAFE strategy and all trachoma endemic districts of the region are covered by the surgery and antibiotics (S \& A) components of SAFE strategy. The prevalence of active trachoma among 1-9 years old children was $>30 \%$ and all residents of the woreda are taking Azithromycin mass drug administration starting in 2014 and it takes three rounds and will continue to five rounds. The MDA coverage of the woreda was $96 \%$ in the 1 st round 2014, 95\% in the 2 nd round 2015, and 93\% in the 3rd round 2016 [7].

The prevalence and associated factors of active trachoma in the study area are not yet determined and the WHO recommends the assessment of active trachoma among 1-9 years old children after MDA of antibiotics. Thus, this study will contribute to the regional and district efforts of trachoma prevention and control through assessment of the level of prevalence in the study area, the implementation of MDA, and identifying factors associated with active trachoma in the community. The findings of this study will also help for the planning of prevention, control and elimination efforts of the disease. This study was aimed to assess the prevalence of active trachoma and associated factors among 1-9 years old children 1 year after three rounds of azithromycin mass administration in Deguatemben woreda.

\section{Methods}

\section{Study area and period}

The study was conducted in Deguatemben woreda, one of the 4 woredas in the Southeast zone of Tigray Regional state that has 24 kebeles (smallest administrative unit in Ethiopia) in which one of them is urban. The current population size of the woreda is estimated to be 150,254 based on the 2007 population census. The woreda has one primary hospital, 5 health centers, and 24 health posts according to the woreda data. There is no ophthalmic professional in any of the health facilities. The study was conducted from 1st March to 30th March 2018.

\section{Study design and population}

We conducted a community-based cross-sectional study among 1-9 years old children. All 1-9 years old children in the selected kebeles were our source of population and we include children from the age of 1-9 years old who were lived for at least 6 months in the study area. Children who are unable to undergo physical examination due to medical illness were excluded from the study. 


\section{Sample size and sample size determination}

The sample size was determined for both objectives. For the first objective, we were determined using a single population proportion formula $\mathrm{n}=(\mathrm{Z} \alpha / 2)^{2} \mathrm{p}(1-\mathrm{p}) / \mathrm{d}^{2}$, where $\mathrm{n}$ is the sample size, $\mathrm{z}$ is the standard normal deviation, set at 1.96 (for 95\% confidence interval [CI]), d is the desired degree of marginal error (taken as 0.05) and $\mathrm{p}$ is the estimated prevalence of active trachoma (18\%) taken from similar community [15]. The minimum sample size is 227 and expecting a $10 \%$ nonresponse rate and a design effect of two the final sample size is 500 . We also determined the second objective, using the associated factor of active trachoma from a study done on the previous time. Sampling was determined based on the double proportion formula on the software of Epi Info StatCalc version 7 after considering the following assumptions; 95\% confidence interval (CI), $80 \%$ power, 1:1 ratio of exposed to non-exposed group, odds ratio (OR) of 2.2 and taking the proportion-1 of $55.2 \%$ and proportion- 2 of $32.8 \%$ number of preschool children as a factor for active trachoma [13]. Finally, with an expected non-response rate of $10 \%$ and the design effect (2.0) the maximum sample size was 502 . Then we took the largest sample size that is 502 .

\section{Sampling techniques and procedure}

The study employed multi-stage with a stratified sampling technique. Initially, the stratification of kebeles into rural and urban strata was made. Seven kebeles (1 urban and 6 rural) were selected from the total kebeles in the district using a simple random sampling technique. Then, probability proportional to size (PPS) used to allocate children aged 1-9 years from each kebeles. Finally, children aged 1-9 years old were selected by a systematic random sampling method using the existing list of households' from the family folder as a sampling frame of health extension works in the selected kebeles. In the case of more than one child 1-9 years old in the selected household, we select one using the lottery method and if in the selected household has no child aged 1-9 years old we used the next household.

\section{Data collection tools and procedures}

Data was collected using a structured and pretested questionnaire from mothers or caregivers. Face to face interview was done with the mothers of children 1-9 years old children and direct observation was conducted to assess the availability and utilization of WASH facilities by trained data collectors.

Besides, trained ophthalmic nurses who participated in the 2013 global trachoma mapping project (GTMP) who are certified for trachoma grading examined the upper tarsal conjunctiva of each child by wearing $2.5 \mathrm{x}$ magnifying loupe and pen torch to assess each eye for the sign of active trachoma. Grading was done according to the WHO simplified grading system [3]. Eyelid eversion (turning out) of the children was done using an aseptic technique by using cotton tip applicators and alcohol used for hand disinfection. Active trachoma was defined as the presence of Trachomatous inflammation follicles (TF) or Trachomatous inflammation (TI) in either eye.

\section{Data quality assurance and management}

The questionnaire was first prepared in English and translated to the local language Tigrigna and then it was again translated back to English. Two days Training was given for both data collectors and supervisors by principal investigator and ophthalmologist. Besides, the ophthalmic nurse has received refresher training with ophthalmologists having well experienced on the grading of trachoma using the WHO grading scheme procedures and he received practical training, PowerPoint, photographic images. One week before the actual data collection period pretest was done in $5 \%$ of the sample ( 25 children) from a similar population outside the study area and based on the findings of the pretest, minor modifications of questions, wordings, phrases and time required to interview respondents was made. Each questionnaire collected from the field was checked for completeness, missed values, and unlikely responses and then manually cleaned up on such indications. Then data were coded and entered into a computer using Epi-Info version 7.0.9.7 for using doubleentry customizing and skip benefit, then after data cleaning, it was exported to SPSS version 20 computer software packages. Data were cross-checked for consistency and accuracy.

\section{Data processing and analysis}

Descriptions of the main findings were done using frequencies, percentages, and summary statistics. The binary logistic regression model was fitted to assess factors associated with active trachoma. The model's fitness was evaluated using the Hosmer -Lemeshow goodness of fit test and if the $p$-value is $>0.05$ that was 0.295 , and then the model was considered as fit otherwise unfit. Factors with p-value $<0.25$ in chi-square (X2) cross-tabulation/ bivariate analysis were entered for multivariate logistic regression analysis. Multicollinearity was checked by a variance inflation factor (VIF) for VIF $>10$ to be significant Multicollinearity but in our data, no variable was with VIF more than the threshold. Backward LR stepwise regression analysis was used for variables to be independent predictors for the outcome variable. Those variables with $p$-value $<0.05$ in the multivariable analysis were considered as independent predictors for active trachoma and odds ratio with a 95\% confidence interval was reported. 


\section{Operational definition}

Clean face: a child who did not have an eye discharge or nasal discharge, fly on the face at the time of data collection [16].

Protected water source: water source protected by construction from outside contamination [18].

Active trachoma: Trachomatous inflammation follicles or Trachomatous inflammation intense [4].

Knowledge: mothers or caregivers of children 1-9 years old children were asked twelve knowledge related questions to assess their knowledge status on trachoma. Correct answers were given score 1 and incorrect answers 0. Mothers who score mean and above of the questions were labeled as "knowledgeable" and those who scored below the mean were labeled as "less knowledgeable" [19].

\section{Results}

\section{Characteristics of participants}

A total of 502 children aged 1-9 years old participated in the study making a response rate of $100 \%$. The median age of children under study was 4 with IQR of 2-6 and more than half 266 (53\%) were in the age group of 1 to 4 years old. Regarding the educational status of children, 323 (64.3\%) were preschool and 172 (34.3\%) were students. [Table 1].

More than one-third of 190(37.8\%) of mothers had no formal education. Regarding the marital and occupational status of the caregivers, 437 (87.1\%) were married and 392 (78.1\%) were housewives respectively. [Table 2].

Four hundred forty-one (87.8\%) mothers reported that they had heard about trachoma. Besides, more than half (53.2\%) of mothers were knowledgeable about trachoma which is computed from the mean of correctly answered twelve questions asked.

Out of 502 households, the assessed latrine was available in 304(60.6\%), and of those who have a latrine, $90 \%$ utilize it. More than $90 \%$ of the latrines are used by all members of the family. Only 61 and 36\% of HHs had solid and liquid waste disposal system respectively. Forty-one percent $(41 \%)$ of $\mathrm{HHs}$ had animals and only $56 \%$ had separate animal sheds. Regarding the source of energy for food cooking 314(62.5\%) HHs use wood or animal dung and the rest use electric. More than $70 \%$ of HHs water source is from protected water source but more than $50 \%$ of HHs spent more than 30 min to fetch water. Only 94 (18.7\%) of HHs wash their child's face more than once per day. Three hundred seventy-two (74.1\%) of mothers reported soap use for washing their child's face but only $45.6 \%$ use always. [Table 3].

\section{Mass drug administration (MDA) related information of study participants}

Out of 502 children who participated in the study 432 (86\%) self-reported from mothers to have received at least one round of azithromycin during previous MDA campaigns. Out of 432 children who received azithromycin during previous MDA 359 (83\%) received three rounds. [Table 3].

The prevalence of active trachoma (TF and or TI) among study participants was $21.5 \%$ (95\% CI: $17.8-$ $25.1 \%)$ in the study community. The prevalence of TF was $18.7 \%$, TI 2.2 and $0.6 \%$ were TF and TI co-infected. The prevalence of active trachoma was slightly higher among males (52\%) than among females (48\%) study participants.

\section{Factors associated with active trachoma among 1-9 years old children}

All independent variables were found statistically significant in chi-square (X2) cross-tabulation/bivariate analysis at the $p$-value of $\leq 0.25$ considered for multivariate regression analysis [Table 4]. On multivariate logistic regression, the odds of having active trachoma was found five times [AOR $(95 \% \mathrm{CI})=5.01(1.79-13.96)]$ higher among children 1 to 4 years old than children 5 to 9 years old. The logistic analysis also revealed that the odds of having active trachoma were almost six times

Table 1 Sociodemographic characteristics of study children participated in the study conducted in Deguatemben district, Tigray, Northern Ethiopia, 2018

\begin{tabular}{|c|c|c|c|}
\hline Variables & Variable category & Frequency $(\boldsymbol{n}=502)$ & Percentage (\%) \\
\hline \multirow[t]{2}{*}{ Sex of child } & Male & 257 & 51.2 \\
\hline & Female & 245 & 48.8 \\
\hline \multirow{3}{*}{$\begin{array}{l}\text { Education status } \\
\text { of child }\end{array}$} & Preschool & 323 & 64.3 \\
\hline & Student & 172 & 34.3 \\
\hline & not attending school & 7 & 1.4 \\
\hline \multirow[t]{2}{*}{ The age group of a child } & 1 to 4 years old & 266 & 53 \\
\hline & 5 to 9 years old & 236 & 47 \\
\hline \multirow[t]{2}{*}{ Number of $<10$ children in the household } & $\leq 2$ children & 455 & 90.6 \\
\hline & $\geq 3$ children & 47 & 9.4 \\
\hline
\end{tabular}


Table 2 Socio-demographic characteristics of mothers participated in the study conducted in Deguatemben district, Tigray, Northern Ethiopia, 2018

\begin{tabular}{|c|c|c|c|}
\hline Variables & Variable category & Frequency $(\boldsymbol{n}=502)$ & Percentage (\%) \\
\hline \multirow{5}{*}{$\begin{array}{l}\text { Educational } \\
\text { Status of } \\
\text { Mothers }\end{array}$} & No formal education & 190 & 37.8 \\
\hline & 1st to 4 th grade & 18 & 3.6 \\
\hline & 5th to 8th & 86 & 17.1 \\
\hline & 9th to 12 th & 125 & 24.9 \\
\hline & college and above & 83 & 16.5 \\
\hline \multirow{2}{*}{$\begin{array}{l}\text { Marital } \\
\text { Status of mothers }\end{array}$} & Married & 437 & 87.1 \\
\hline & Divorced & 65 & 12.9 \\
\hline \multirow{3}{*}{$\begin{array}{l}\text { Occupational status } \\
\text { of mothers }\end{array}$} & Housewife & 392 & 78.1 \\
\hline & Government employee & 34 & 6.8 \\
\hline & Merchant & 76 & 15.1 \\
\hline \multirow[t]{2}{*}{ Residency } & Rural & 418 & 83.3 \\
\hline & Urban & 84 & 16.7 \\
\hline \multirow{4}{*}{$\begin{array}{l}\text { Age group } \\
\text { of mothers }\end{array}$} & 20-24 years & 28 & 5.6 \\
\hline & 25-29 years & 132 & 26.3 \\
\hline & $30-34$ years & 230 & 45.8 \\
\hline & $\geq 35$ years & 112 & 22.3 \\
\hline \multirow[t]{2}{*}{ TV/Radio in the $\mathrm{HH}$} & Yes & 250 & 49.8 \\
\hline & No & 252 & 50.2 \\
\hline \multirow[t]{2}{*}{ Number of family in $\mathrm{HH}$} & $\leq 5$ families & 385 & 76.7 \\
\hline & $\geq 6$ families & 117 & 23.3 \\
\hline \multirow[t]{2}{*}{ Number of under 10 children in the $\mathrm{HH}$} & $\leq 2$ children & 455 & 90.6 \\
\hline & $\geq 3$ children & 47 & 9.4 \\
\hline
\end{tabular}

[AOR $(95 \%$ CI $)=5.84(1.79-13.96)]$ higher among children who don't use soap for face washing than their counterparts. The odds of active trachoma was more than nine times $[$ AOR $(95 \%$ CI $)=9.35(4.93-67.32)$ higher among children who do not wash their face in daily bases compared to those who wash more than once per day. Children with unclean faces were more than eighteen times $[$ AOR $(95 \% \mathrm{CI})=18.22(4.93-69.32)]$ more likely to have active trachoma than children with a clean face. The odds of having active trachoma was also 0.06 [AOR (95\% CI) $=0.06(0.02-0.19)]$ times less likely among children from mothers with good knowledge than children whose mothers were less knowledgeable. [Table 4].

\section{Discussion}

The prevalence of active trachoma in the district was found to be $21.5 \%(17.8-25.1 \%) 1$ year after three rounds of mass drug administration. Though there is a decline in the prevalence of TF from $44.7 \%$ in the baseline to $18.7 \%$ after three rounds of MDA, it is far above the $10 \%$ treatment threshold [11]. This might be related to the effectiveness of the trachoma control program of MDA with a high coverage rate.
The prevalence of active trachoma in our study area was consistent with finding from district level studies in different parts of the country including; Baso Liben 24.1\%, Gongi Kollela 23.1\%, Demba 18\%, Kersa 25.2\%, Dera $18.6 \%$, Cheha districts $22.8 \%$ and Maksegnit Town $23.8 \%[15,16,19-23]$. But the prevalence in our study area was lower than the district level study conducted in Ankober 53.9\%, Gazegibela 52.4\%, Zala 36.7\% [12, 13, 24]. This might be the provision of Mass drug administration in our study area was better effective compare to those study areas.

In contrast, the prevalence of active trachoma among children in our study is higher than the study findings of Ghana 5.6 and 3.5\%, and Gambia 2.8\% after control activities $[25,26]$. Besides, it is higher than the study findings of evaluation units of Welkait, Tsegedae, Tahtay, and Laelay-Adiabo even without any intervention according to the GTMP result of Tigray region [11]. This difference could be attributed due to the difference in the study setting, study period, intervention and baseline difference in the prevalence of active trachoma in the communities. In addition to this, hyper-endemic districts may require more rounds of MDA with an even high coverage rate as suggested by West SK. et al.,2011 [27]. 
Table 3 Environmental, hygiene and sanitation characteristics of study participants in Deguatemben district, Tigray, Northern Ethiopia, 2018

\begin{tabular}{|c|c|c|c|}
\hline Variables & Category & $\begin{array}{l}\text { Frequency } \\
(\boldsymbol{n}=502)^{*}\end{array}$ & $\begin{array}{l}\text { Percentage } \\
\text { (\%) }\end{array}$ \\
\hline \multirow[t]{2}{*}{ Access to latrine } & Yes & 304 & 60.6 \\
\hline & No & 198 & 39.4 \\
\hline \multirow[t]{2}{*}{ Latrine utilization $(n=304)$} & Yes & 295 & 97 \\
\hline & No & 9 & 3 \\
\hline \multirow[t]{3}{*}{ Who use latrine $(n=295)$} & Adults & 21 & 7.1 \\
\hline & Children & 4 & 1 \\
\hline & All family members & 270 & 91.8 \\
\hline \multirow[t]{2}{*}{ The solid waste disposal system } & Proper pit & 306 & 61 \\
\hline & Open field & 196 & 39 \\
\hline \multirow[t]{2}{*}{ Liquid waste disposal } & Yes & 182 & 36.3 \\
\hline & No & 320 & 63.7 \\
\hline \multirow[t]{2}{*}{ Food cooking } & Kitchen & 79 & 15.7 \\
\hline & Inside house & 423 & 84.3 \\
\hline \multirow[t]{2}{*}{ Window in kitchen $(n=79)$} & Yes & 75 & 94.9 \\
\hline & No & 4 & 5.1 \\
\hline \multirow[t]{2}{*}{ Presence of animals in $\mathrm{HH}$} & Yes & 207 & 41.6 \\
\hline & No & 295 & 58.4 \\
\hline \multirow[t]{2}{*}{ Animal's living condition $(n=207)$} & Separate animal shed & 117 & 56 \\
\hline & With humans & 90 & 44 \\
\hline \multirow[t]{2}{*}{ Source of energy for cooking } & Wood/animal dung & 314 & 62.5 \\
\hline & Electricity & 188 & 37.5 \\
\hline \multirow[t]{4}{*}{ Water source } & Pipe & 97 & 19.3 \\
\hline & Protected spring & 267 & 53 \\
\hline & Unprotected spring & 105 & 20.9 \\
\hline & River & 33 & 6.6 \\
\hline \multirow[t]{4}{*}{ Time spent to fetch water } & Within compound & 97 & 19.3 \\
\hline & Less than $30 \mathrm{~min}$ & 119 & 23.7 \\
\hline & 30 to $59 \mathrm{~min}$ & 188 & 37.5 \\
\hline & More than $60 \mathrm{~min}$ & 98 & 19.5 \\
\hline \multirow[t]{3}{*}{ Amount of water /head/day } & Less than 201 & 197 & 39.2 \\
\hline & 20 to 601 & 236 & 47 \\
\hline & More than 601 & 69 & 13.7 \\
\hline \multirow[t]{3}{*}{ Frequency of face washing } & More than one per day & 94 & 18.7 \\
\hline & Only once per day & 384 & 76.5 \\
\hline & Not daily & 24 & 4.8 \\
\hline \multirow[t]{2}{*}{ Soap use } & Yes & 372 & 74.1 \\
\hline & No & 130 & 25.9 \\
\hline \multirow[t]{2}{*}{ Frequency of soap use $(n=372)$} & Always & 170 & 45.7 \\
\hline & Some times & 202 & 54.3 \\
\hline
\end{tabular}

${ }^{*} n=502$ unless specified 
Table 4 Factors associated with active trachoma among 1-9 years old children in Deguatemben district, Tigray, Northern Ethiopia, 2018

\begin{tabular}{|c|c|c|c|c|}
\hline Factors & Active Trachoma & No Active Trachoma & $\operatorname{COR}(95 \% \mathrm{Cl})$ & AOR(95\%Cl) \\
\hline \multicolumn{5}{|l|}{ The age group of child } \\
\hline 1 to 4 years old & 78 & 188 & $2.85(1.79-4.56)^{*}$ & $5.01(1.79-13.96)^{* *}$ \\
\hline 5 to 9 years old & 30 & 206 & 1.00 & \\
\hline \multicolumn{5}{|l|}{ Access to latrine } \\
\hline Yes & 55 & 249 & 1.00 & \\
\hline No & 53 & 145 & $1.66(1.08-2.54)^{*}$ & $2.21(0.82-5.98)$ \\
\hline \multicolumn{5}{|l|}{ Solid waste disposal system } \\
\hline Proper waste pit & 57 & 249 & 1.00 & \\
\hline Open field & 51 & 145 & $1.54(1.01-2.36)^{*}$ & $1.02(0.33-3.18)$ \\
\hline \multicolumn{5}{|l|}{ Liquid waste disposal system } \\
\hline Yes & 27 & 155 & 1.00 & \\
\hline No & 81 & 239 & $1.95(1.20-3.15)^{*}$ & $0.82(0.23-2.99)$ \\
\hline \multicolumn{5}{|l|}{ Animal's living condition } \\
\hline Separate animal shed & 26 & 91 & 1.00 & \\
\hline No separate animal shed & 32 & 60 & $1.87(1.01-3.44)^{*}$ & $2.73(0.97-7.64)$ \\
\hline \multicolumn{5}{|l|}{ Child face washing frequency } \\
\hline More than once per day & 28 & 66 & 1.00 & \\
\hline Only once per day & 64 & 320 & $0.47(0.28-0.79)^{*}$ & $0.48(0.17-1.41)$ \\
\hline Not daily & 16 & 8 & $4.71(1.81-12.27)^{*}$ & $9.35(4.93-67.32)^{* *}$ \\
\hline \multicolumn{5}{|l|}{ Soap use for face washing } \\
\hline Yes & 60 & 312 & 1.00 & \\
\hline No & 48 & 82 & $3.04(1.94-4.78)^{*}$ & $5.84(1.79-13.96)^{* *}$ \\
\hline \multicolumn{5}{|l|}{ Number of MDA rounds } \\
\hline One & 10 & 37 & $1.51(0.71-3.22)$ & $1.93(0.26-14.54)$ \\
\hline Two & 10 & 18 & $3.12(1.36-7.09)^{*}$ & $0.40(0.02-9.21)$ \\
\hline Three & 54 & 302 & 1.00 & \\
\hline \multicolumn{5}{|l|}{ Clean face } \\
\hline Yes & 11 & 229 & 1.00 & \\
\hline No & 97 & 165 & $12.24(6.36-23.56)^{*}$ & $18.22(4.93-69.32)^{* *}$ \\
\hline \multicolumn{5}{|l|}{ Educational status of mothers } \\
\hline No regular education & 37 & 153 & $1.98(0.91-4.34)$ & $0.43(0.07-2.45)$ \\
\hline Grade 1 to 4 th & 4 & 14 & $2.35(0.63-8.69)$ & $0.63(0.06-7.02)$ \\
\hline Grade 5th to 8th & 22 & 64 & $2.83(1.22-6.58)^{*}$ & $0.53(0.07-3.88)$ \\
\hline Grade 9 th to 12 th & 36 & 89 & $3.33(1.51-7.35)^{*}$ & $1.91(0.28-13.28)$ \\
\hline College and above & 9 & 74 & 1.00 & \\
\hline \multicolumn{5}{|c|}{ Mothers knowledge on trachoma } \\
\hline Knowledgeable & 26 & 241 & $0.20(0.12-0.33)^{*}$ & $0.06(0.02-0.19)^{* *}$ \\
\hline Less knowledgeable & 82 & 153 & 1.00 & \\
\hline
\end{tabular}

${ }^{*}=$ significant on bivariate, ${ }^{* *}=$ significant on multivariable analysis at $p$-value $<0.05$ $C O R$ crude odds ratio and $A O R$ adjusted odds ratio, $1.00=$ referent.

Active trachoma was five times more likely to happen among children from 1 to 4 years old than children 5 to 9 . This finding is in line with the findings of the study conducted in Ankober and southern nations and nationalities people (SNNP) [24, 28]. This may be due to young children may not able to care about themselves and play in dirty places than older children. 
Children who do not use soap for face washing were almost six times to have active trachoma than their counterparts. This finding was in line with the study finding conducted in Baso Liben district [19]. This might be due to the ability of soap to clear microorganisms.

Children who do not wash their faces on a daily bases were found to be more than nine times to have active trachoma compared to those who wash their faces more than once per day. This result is consistent with the study findings of Baso Liben, Gonji kollela, Gazigeabella, and Zala districts $[12,13,19,21]$. This might be due to the habit of face washing may affect the transmission of the disease from person to person.

The finding of this study also revealed that children with unclean faces were more than eighteen times to have active trachoma than their counterparts. Other studies also reported similar findings which include; a study conducted in Dembia and Cheha districts $[15,16]$. This may be due to the ability of the secretions to attract eye-seeking flies which increases the risk of transmission trachoma from one person to another [29-31].

Children from knowledgeable mothers were found to be 0.07 times less likely to have active trachoma compared to children from less knowledgeable mothers. This finding was in line with the study result from Baso Liben and Zala districts $[13,19]$. The possible explanation for this difference could be the difference in access to information, education and communication media on trachoma prevention, community-based health education by trained health workers.

\section{Strength and limitations of the study}

As the strength of our study, Tetracycline eye ointment was provided to those who had active trachoma two tubes to apply for 6 weeks. Being community-based cross-sectional and the grading of trachoma was done by certified, having more experience in trachoma grading and participated in the pre-intervention assessment of the global trachoma mapping project in the Tigray region. However, the study might have some limitations that first; the cross-sectional nature of the study design does not confirm the definitive cause and effect relationship. For those children who are older, we have not taken into consideration their practice on face washing. The questionnaires were designed and translated into a local language and re-translated to English. This could be also a recipe for bias. Furthermore, the study may prone to reporting bias since some of the data are collected based on self-reported information.

\section{Conclusion}

Although the prevalence of active trachoma among 1-9 years old children indicate a decline 1 year after three rounds of MDA in the district, it is still higher than the
WHO threshold prevalence of $20 \%$ which is used to determine trachoma as a severe public health problem and it is far from the elimination of trachoma as a public health problem in a community as when there is less than $5 \%$ active trachoma in children [32,33]. Not washing the face daily, not using soap for face washing; unclean face, younger child age and mother's knowledge on trachoma were found to be independent predictors of active trachoma in the district 1 year after 3 years of MDA with azithromycin.

The regional health bureau and woreda health office should implement all components of the SAFE strategy emphasizing personal hygiene (facial cleanness) and environmental improvement.

\section{Abbreviations}

TF: Trachomatous inflammation Follicular; TI: Trachomatous inflammation intense; TS: Trachomatous scarring; TT: Trachomatous Trichiasis; CO: Corneal opacity; SAFE: Surgery, antibiotics, facial cleanness, and environmental improvements; WHO: World health organization; HH: household

\section{Acknowledgments}

We would like to thank Mekelle University and Tigray regional state health bureau. We have thanks to the Degua-Temben health office for giving us needed data and material. We have special thanks to our data collectors and study participants.

\section{Authors' contributions}

GR contributed to the conceptualization of the study, recruited study participants, funding acquisition and made data collection, study investigation, and data analysis. DY contributed to providing methodology, study investigation, and supervision, data analysis, validation. AG contributed to providing methodology, study investigation, and supervision, data analysis, validation, writing manuscript. In the end, all authors have read and approved the manuscript.

\section{Funding}

Mekelle University is the funder of this study. The sponsor of the study had no role in study design, data collection, data analysis or interpretation, but provided certain training materials, organizing the training and did review this report before submission for publication. The corresponding author had full access to all the data in the study and had final responsibility for the decision to submit for publication.

\section{Availability of data and materials}

All the data supporting the findings is contained within the manuscript, when there is in need the data-set used for the present study's conclusion can be accessible from the corresponding author on reasonable request.

\section{Ethics approval and consent to participate}

Ethical clearance was obtained from the Health Research Ethics Review Committee (HRERC) of Mekelle University. Permission letter was also taken from the Tigray Regional Health bureau to Deguatemben woreda health office. Then the woreda health office wrote a letter to the study kebeles. Child assent and informed verbal and then written consent were obtained from the sampled children and their parents respectively. The respondents were also informed that they have the full right to withdraw or refuse at any time from the process. Confidentiality of information given by each respondent was kept properly and anonymity was explained clearly for the participant. Tetracycline eye ointment was provided to those who had active trachoma two tubes to apply for 6 weeks.

\section{Consent for publication}

Not Applicable.

Competing interests

The authors declare that they have no competing interests. 


\section{Author details}

${ }^{1}$ Tigray Regional Health Bureau, Mekelle, Tigray, Ethiopia. ${ }^{2}$ College of Health Sciences, Mekelle University, P.O.BOX:1871 Mekelle, Tigray, Ethiopia.

Received: 6 January 2020 Accepted: 16 March 2020

Published online: 15 April 2020

\section{References}

1. Communicable Diseases Network Australia. In: Health D, editor. CDNA National Guidelines for the public health Management of Trachoma; 2014.

2. Center for Disease Control. Guideline for the management of Trachoma in the Northern Territory. seconded: CDC; 2008

3. Taylor HR, West SK, Katala S, Foster A. Trachoma: evaluation of a new grading scheme in the United Republic of Tanzania. Bull World Health Organ. 1987:65(4):485.85-8.

4. Thylefors B, Dawson CR, Jones BR, West SK, Taylor HR. A simple system for the assessment of trachoma and its complications. Bull World Health Organ. 1987;65(4):477

5. Smith JL, Flueckiger RM, Hooper PJ, Polack S, Cromwell EA, Palmer SL, Emerson PM, Mabey DC, Solomon AW, Haddad D, Brooker SJ. The geographical distribution and burden of trachoma in Africa. PLoS Negl Trop Dis. 2013 Aug 8;7(8):e2359.

6. Negrel AD, Taylor HR, West S. World Health Organization Prevention of blindness and deafness; Guideline for rapid assessment for blinding trachoma. WHO/PBD/GET/00.8, editor: WHO; 2001.

7. Light for the World. Trachoma and Human Resource Development: Vision and Development ophthalmology in the development Cooperation issue. 2017.

8. Ramadhani AM, Derrick T, Macleod D, Holland MJ, MJ B. Eliminating trachoma: accelerating towards 2020. Geneva: WHO Alliance for the Globa Elimination of Trachoma by; 2020. https://www.who.int/trachoma/news/ News_Trachoma_Towards_2020/en/.

9. Solomon AW, Peeling RW, Foster A, Mabey DC. Diagnosis and assessment of trachoma. Clin Microbiol Rev. 2004 Oct 1;17(4):982-1011.

10. Berhane Y, Worku A, Bejiga A, Adamu L, Alemayehu W, Bedri A, Haile Z, Ayalew A, Adamu W, Gebre T, Kebede TD. National survey on blindness, low vision and trachoma in Ethiopia: methods and study clusters profile. Ethiop J Health Dev. 2007;21(3):185-203.

11. Sherief ST, Macleod C, Gigar G, Godefay H, Abraha A, Dejene M, Kello AB, Belete A, Assefa Y, Willis R, Chu BK. The prevalence of trachoma in Tigray Region, Northern Ethiopia: results of 11 population-based prevalence surveys completed as part of the global trachoma mapping project. Ophthalmic Epidemiology. 2016;23(sup1):94-9.

12. ZA AA, Getu WY. Prevalence of active trachoma and associated risk factors among children in Gazegibela district of Wagehemra Zone, Amhara region, Ethiopia: a community-based cross-sectional study. Trop Dis Travel Med Vaccines. 2016;2(1):5.

13. Mengistu K, Shegaze M, Woldemichael K, Gesesew H, Markos Y. Prevalence and factors associated with trachoma among children aged 1-9 years in Zala district, Gamo Gofa Zone, Southern Ethiopia. Clinical Ophthalmology (Auckland, NZ). 2016;10:1663.

14. Kalua K, Chirwa T, Kalilani L, Abbenyi S, Mukaka M, Bailey R. Prevalence and risk factors for trachoma in central and southern Malawi. PLoS One. 2010;5(2):e9067.

15. Ferede AT, Dadi AF, Tariku A, Adane AA. Prevalence and determinants of active trachoma among preschool-aged children in Dembia District, Northwest Ethiopia. Infect Dis Pov. 2017:6(1):128.

16. Admassu F, Bayu S, Bejiga A, Amare B. Active trachoma two years after three rounds of azithromycin mass treatment in Cheha district Gurage zone, Southern Ethiopia. BMC Pediatrics. 2013;13(1):199.

17. Kuper H, Solomon AW, Buchan J, Zondervan M, Foster A, Mabey D. A critical review of the SAFE strategy for the prevention of blinding trachoma. Lancet Infect Dis. 2003 Jun 1;3(6):372-81.

18. Tadesse B, Worku A, Kumie A, Yimer SA. Effect of water, sanitation and hygiene interventions on active trachoma in north and south Wollo zones of Amhara region, Ethiopia: a quasi-experimental study. PLoS Negl Trop Dis. 2017 Nov 10;11(11):e0006080.

19. Ketema K, Tiruneh M, Woldeyohannes D, Muluye D. Active trachoma and associated risk factors among children in Baso Liben District of east Gojjam, Ethiopia. BMC Public Health. 2012 Dec;12(1):1105.

20. Shiferaw D, Moges HG. Risk factors for active trachoma among children aged 1-9 years in Maksegnit town, Gondar Zuria District, Northwest Ethiopia. Saudi J Health Sci. 2013;2(3):202-6.
21. Nigusie A, Berhe R, Gedefaw M. Prevalence and associated factors of active trachoma among children aged 1-9 years in rural communities of Gonji Kolella district, West Gojjam zone, north West Ethiopia. BMC Research Notes. 2015:8(1):641.

22. Ejigu M, Kariuki MM, llako DR, Gelaw Y. Rapid trachoma assessment in kersa district, Southwest Ethiopia. Ethiop J Health Sci. 2013;23(1):1-9.

23. Alemayehu M, Koye DN, Tariku A, Yimam K. Prevalence of active trachoma and its associated factors among rural and urban children in Dera Woreda, Northwest Ethiopia: a comparative cross-sectional study. Biomed Res Int. $2015 ; 2015$.

24. Golovaty I, Jones L, Gelaye B, Tilahun M, Belete H, Kumie A, Berhane Y, Williams MA. Access to water source, latrine facilities and other risk factors of active trachoma in Ankober, Ethiopia. PLoS One. 2009;4(8),

25. Hagan M, Yayemain D, Ahorsu F, Aboe A. Prevalence of active trachoma two years after control activities. Ghana Med J. 2009:43(2):54.

26. Burton MJ, Holland MJ, Makalo P, Aryee EA, Sillah A, Cohuet S, Natividad A, Alexander ND, Mabey DC, Bailey RL. Profound and sustained reduction in chlamydia trachomatis in the Gambia: a five-year longitudinal study of trachoma endemic communities. PLoS Negl Trop Dis. 2010 Oct 5;4(10):e835.

27. West SK, Munoz B, Mkocha H, Gaydos CA, Quinn TC. The number of years of annual mass treatment with azithromycin needed to control trachoma in hyper-endemic communities in Tanzania. J Infect Dis. 2011 Jul 15:204(2): 268-73.

28. Adera TH, Macleod C, Endriyas M, Dejene M, Willis R, Chu BK, Letamo Y, Misganaw T, Mesele T, Mekonnen E, Sisay A. Prevalence of and risk factors for trachoma in Southern Nations, Nationalities, and Peoples' Region, Ethiopia: results of 40 population-based prevalence surveys carried out with the Global Trachoma Mapping Project. Ophthalmic Epidemiology. 2016; 23(sup 1):84-93.

29. Emerson PM, Lindsay SW, Alexander N, Bah M, Dibba SM, Faal HB, Lowe K McAdam KP, Ratcliffe AA, Walraven GE, Bailey RL. Role of flies and provision of latrines in trachoma control: cluster-randomized controlled trial. Lancet. 2004:363(9415):1093-8.

30. Emerson PM, Bailey RL. Trachoma and fly control. Community Eye Health. 1999;12(32):57.

31. West SK, Emerson PM, Mkocha H, Mchiwa W, Munoz B, Bailey R, Mabey D. Intensive insecticide spraying for fly control after mass antibiotic treatment for trachoma in a hyperendemic setting: a randomized trial. Lancet. 2006; 368(9535):596-600.

32. Bourne RR, Stevens GA, White RA, Smith JL, Flaxman SR, Price H, Jonas JB, Keeffe J, Leasher J, Naidoo K, Pesudovs K. Causes of vision loss worldwide, 1990-2010: a systematic analysis. Lancet Glob Health. 2013;1 (6):e339-49.

33. International Coalition for Trachoma Control. Trachoma Free Africa Fact 592 Sheet ICTC [Available at https://www.trachomacoalition.org/sites/default/files/ content/resources/files/TFA\%20fact\%20sheet.pdf. Accessed on May 28, 2017.

\section{Publisher's Note}

Springer Nature remains neutral with regard to jurisdictional claims in published maps and institutional affiliations.

Ready to submit your research? Choose BMC and benefit from:

- fast, convenient online submission

- thorough peer review by experienced researchers in your field

- rapid publication on acceptance

- support for research data, including large and complex data types

- gold Open Access which fosters wider collaboration and increased citations

- maximum visibility for your research: over $100 \mathrm{M}$ website views per year

At BMC, research is always in progress.

Learn more biomedcentral.com/submissions 